\title{
Redes Sociais de Informação: uma história e um estudo de caso
}

\section{Gonçalo Costa Ferreira}

\begin{abstract}
Mestrando em Ciência da Informação na Escola da Comunicações e Artes da Universidade de São Paulo
\end{abstract}

Vivemos em um mundo fluido e caracterizado pela complexidade. Dinamismo da relação entre as partes, sistemas abertos, imprevisibilidade, não-linearidade, auto-organização, adaptabilidade, criatividade, instabilidade, emergência, incerteza, conectividade e fluxo são algumas das marcas da contemporaneidade, na qual a informação e as redes emergem como elementos catalisadores da realidade. Em um contexto social, o intercâmbio de recursos informacionais dá-se por meio das relações que os agentes sociais estabelecem entre si. Os entrelaçados de relações que assim se formam, constituem as redes sociais, através das quais flui a informação. Com esta perspectiva, importa tentar responder à pergunta: "como se relacionam fluxos sociais de Informação com topologias e dinâmicas das Redes Sociais?" Neste trabalho, procurou-se dar um panorama histórico dos conceitos de redes e redes sociais, descrever sinteticamente o método de Análise de Redes Sociais (ARS) e ilustrar o comportamento informacional em contexto organizacional, com um estudo de caso de Redes Sociais de Informação.

Palavras-chave: Informação; Redes sociais; Análise de Redes Sociais; ARS; Organizações.

\section{Information social networks: one history and one case study}

We live in a fluid world characterized by complexity. Dynamism of the relationship between agents, open systems, unpredictability, nonlinearity, self-organization, adaptability, creativity, instability, emergence, uncertainty, connectivity and flow are some of the hallmarks of contemporaneity, where Information and Networks emerge as catalysts of reality. In the social 
context, the exchange of information resources takes place through social relations established between social agents. The formed intertwined relationships are the Social Networks through which Information flows. From this point of view, we should try to answer the question, "how does social information flows relate to the topology and dynamics of Social Networks?" In this paper, we provide a historical overview of networks and social networks concepts, briefly describe the method of Social Networks Analysis (SNA) and illustrate the information behavior in organizations with a case study of information social networks.

Keywords: Information; Social networks; Social Network Analysis; SNA; Organizations.

Recebido em 03.09.2010 Aceito em 30.07.2011

\section{Introdução}

Manuel Castells (1999) advoga que somos uma Sociedade em Rede, que vivemos a Era da Informação e alerta para o fato dessa nova morfologia social alterar profundamente os fluxos de informação, a cultura e os modos de produção. Dos mais variados quadrantes da literatura científica, a informação e as redes (sociais ou não) são abordados como dois assuntos de extrema relevância, estando no topo das agendas científica, social e cultural, na atualidade. Este trabalho tem por objeto, simultaneamente, informação e redes sociais, procurando contribuir para um aumento da capacidade analítica de responder à pergunta: como, em contexto organizacional, se relacionam fluxos de informação com a topologia e dinâmica de redes sociais subjacentes?

Hoje, sabemos mais sobre redes do que no início do séc. $X X$, quando surgiram as primeiras tentativas de explicar fenômenos em rede. Depois do nascimento da sociometria, nas décadas de 20 e 30, e das redes randômicas das décadas de 50 e 60, sabemos que as redes sociais são mundos pequenos, como podemos classificá-las, calcular várias de suas grandezas e temos modelos que incorporam o crescimento das redes e a não aleatoriedade das suas conexões. Entretanto e apesar dos muitos e grandes avanços feitos nas ultimas décadas, de acordo com Mark Newman (2003), o estudo das redes está, ainda, na sua infância e não temos, como temos em outros campos, um arcabouço teórico e um programa sistemático para caracterizar as suas estruturas. Não temos a certeza de estar formulando as perguntas certas e ainda não sabemos se as medidas que usamos são as únicas grandezas importantes a se medir ou mesmo se elas são as mais importantes. 


\section{Uma breve história}

O termo rede tem origem etimológica no vocábulo latim rete e assume, hoje em dia, diversos significados. Pode significar espécie de malha formada por um entrelaçado de fios, cordas, arames ou outro material; artefato para fins de apresamento ou retenção do animal desejado; tecido de malha metálica usado para formar vedações. Pode significar, também, conjunto de pessoas, estabelecimentos ou organizações que trabalham comunicando entre si; organização de espionagem implantada em um país; entrelaçamento de nervos e fibras; conjunto de vias ou de meios de transporte ferroviário, rodoviário ou aéreo; sistema interligado de meios de comunicação; sistema interligado de computadores e seus periféricos e, em sentido figurado, pode, também, significar emaranhado de coisas ou de circunstâncias, complicação, cilada, engano ou logro. De acordo com Marteleto (2007), o conceito de rede não é um aporte próprio do século $\mathrm{XX}$, mas pelo contrário, traz, na sua significação, a memória da sua origem orgânica e próxima do imaginário do corpo desde Hipócrates (Cós, 460 - Tessália, 377 a. C. ), considerado, por muitos, o pai da medicina ocidental moderna.

No séc. XVIII, a cidade de Königsberg, atualmente Kaliningrad, na Rússia, tinha sete pontes, cinco das quais ligavam a ilha Kneiphof, cercada pelo rio Pregel, com o restante da cidade. Um intrigante problema assolava a população local: seria possível encontrar um caminho atravessando as sete pontes sem nunca atravessar uma mesma ponte duas vezes? Leonhard Euler foi um proeminente matemático e físico suíço, que viveu em São Petersburgo, até o ano da sua morte, em 1783. Em 1736, propôs a solução para o problema das pontes de Königsberg, oferecendo uma rigorosa prova matemática de que não existia um caminho que passasse por todas as sete pontes uma única vez. Além de resolver o problema das pontes de Königsberg, Euler, de forma não intencional, iniciou uma nova área da matemática, conhecida como teoria dos grafos. Essa teoria é, hoje, a base de todo o conhecimento sobre redes.

É, no inicio do séc. $X X$, que surge a ideia de rede social, a ideia de que as relações sociais compõem um tecido que condiciona a ação dos indivíduos nele inseridos. A metáfora de tecido ou rede foi inicialmente usada na sociologia, para associar o comportamento individual à estrutura a qual ele pertence e transformou-se em uma metodologia denominada sociometria, cujo instrumento de análise se apresenta na forma de um sociograma. Apesar de haver um grande consenso entre os cientistas sociais de que Jacob Moreno, com seu trabalho sobre padrões de amizade, em 1934, foi o fundador da sociometria, Freeman (1996) argumenta que há trabalhos anteriores de Almack (1922), Wellman (1926), ChevelevaJanovskaja (1927), Bott (1928), Hubbert (1929) e Hagman (1933), anteriores ao trabalho de Moreno (1934). 
Mas, como se formam as redes? Quais são as leis que governam o surgimento de cada um dos seus elementos e estrutura? Estas questões permaneceram sem qualquer resposta até meados do séc. $X X$, quando, exatamente em 1951, os norte-americanos Ray Solomonoff e Anatol Rapoport publicaram Connectivity of Random Net e introduziram o conceito de redes randômicas. Entre 1958 e 1968, os matemáticos húngaros Paul Erdös e Alfréd Rényi publicaram oito artigos que revolucionaram o estudo das redes e estabeleceram a teoria randômica dos grafos. Erdös e Rényi entendiam os grafos e o mundo que os mesmos representavam como fundamentalmente aleatórios, propondo que as ligações entre os vértices das redes fossem, também, aleatórias (BARABÁSI, 2009).

Entretanto, das ciências sociais surgem os pioneiros da Análise de Redes Sociais (ARS). Da psicologia social, o já citado Moreno (1934) e, ainda, Newcomb (1935-39) Bavelas (1950) e Cartwright (1953); e da antropologia, Michel e John Barnes (1954). À Barnes é atribuído o primeiro uso do termo rede social (social network), quando, em 1954, começou a usá-lo, sistematicamente, para mostrar os padrões dos laços, incorporando os conceitos tradicionalmente usados, quer pela sociedade quer pelos cientistas sociais.

Nos EUA, em 1964, vivia-se o auge da guerra fria. Paul Baran, que trabalhava como investigador na RAND Corporation, desenhou uma proposta para o sistema de comunicações norte-americano que, para fazer face à ameaça soviética, fosse invulnerável a um possível ataque nuclear. Baran (1964) classificou dois tipos fundamentais de redes: as centralizadas e as distribuídas. As primeiras, que definem uma estrutura hierárquica, têm um nó central que, se for eliminado, afetará toda a rede. As redes distribuídas são redes cuja estrutura forma uma malha, em que os nós têm a mesma importância entre si e, para alcançar um deles, existem vários caminhos possíveis. Isto significa que, ao contrário das centralizadas, a eliminação de um ponto não afetará significativamente a estrutura da rede. Entretanto, mais rigoroso do que falar em redes centralizadas ou distribuídas é referirmo-nos ao grau de centralização de cada rede.

Um dos primeiros, seguramente um dos mais importantes, estudos quantitativos de estrutura de redes sociais foi levado a cabo por Stanley Milgram (1967), um psicólogo social e professor de Harvard. Milgram (1967) lançou-se em um experimento social com o objetivo de encontrar a distância entre duas pessoas quaisquer nos EUA, sendo que a pesquisa consistiu em enviar cartas a várias pessoas em Nebraska, solicitando-Ihes que as remetessem para outras pessoas residentes em Massachusetts. Como condição, as pessoas deveriam sempre passar as cartas em mãos para alguém que conhecessem pelo primeiro nome, que, por sua vez, fariam o mesmo com outras pessoas de suas relações pessoais que fossem capazes de alcançar os destinatários, ou seja, as cartas deveriam 
chegar ao seu destino diretamente ou via a opção amigo de um amigo. 0 número médio de pessoas para fazer chegar uma carta ao alvo foi de 5,5, que arredondado é 6 - os famosos seis graus de separação. Ao contrário do que muitas pessoas pensam, não foi Milgram que cunhou a expressão seis graus de separação. Essa expressão teve sua origem em uma peça de teatro criada por John Guare, em 1990. A principal contribuição de Milgram foi chamar a atenção para o quanto estamos conectados e o fenômeno revelado pela pesquisa passou a ser conhecido pelo conceito de mundo pequeno (small-world). Conhecendo ou não os estudos de Erdös e Rényi (1958-68), Milgram escreveu que a sociedade não é construída por conexões randômicas entre pessoas, mas que tende a ser fragmentada em classes e cliques sociais, antecipando algo que veio a ser provado analiticamente no ocaso do séc. XX.

Antes disso, porém, Mark Granovetter (1973; 1983) define e explora - conceito da força dos laços fracos (strength of weak ties), argumentando que os laços fracos, ao contrário do que possa parecer, em um primeiro momento de análise, são de extraordinária importância na difusão de informação e no acesso ao novo, tendo um papel muito importante na vida social dos individuos, grupos e sociedades. A outra grande contribuição para a teoria de redes sociais é trazida por Ronald Burt, que publicou structural holes em 1992. Buracos estruturais são falhas na estrutura da rede que podem ser estrategicamente preenchidas por ligações entre um ou mais elos, de forma a unir outros atores. $O$ conceito está ligado às ideias de capital social, na medida em que quem estabelece a conexão entre duas pessoas que não estão ligados, pode controlar essa comunicação (SCHULTZ-JONES, 2009).

O mundo das redes aleatórias começou a mudar quando Duncan Watts e Steve Strogatz (1998) sugeriram que a densidade de conexões de alguns vértices de muitas redes reais é tipicamente maior do que em um grafo aleatório com o mesmo número de vértices e ligações. Essa tendência ao agrupamento dos nós é quantificada pelo coeficiente de clusterização ou agrupamento e foi utilizado pela primeira vez por esses autores nesse artigo, onde relatam algumas das primeiras observações feitas em redes reais, indicando que as mesmas tinham propriedade que iam além dos grafos aleatórios.

Em 2002, Albert-László Barabási dá o passo seguinte nas descobertas do mundo das redes. Nota-se que existem dois aspectos genéricos das redes reais que não estão incorporadas nos modelos anteriores de Erdös-Rényi (1958-68) e Watts-Strogatz (1998). Por um lado, o crescimento das redes e do número de vértices e, por outro, a probabilidade de que um novo vértice se conecte a um outro vértice existente na rede não é aleatória, mas exibe a propriedade de ligação preferencial. O modelo de escala livre proposto por Barabási (2009), incorpora, assim, esses dois aspectos, o crescimento e as ligações preferenciais. 
Hoje, sabemos que as redes sociais são caracterizadas por laços fortes, laços fracos e buracos estruturais, que são mundos pequenos, e temos modelos que incorporam o crescimento das redes e a não aleatoriedade de conexão. Com a contribuição de autores de diversas áreas do conhecimento como Albert-Lázló Barabási (1999; 2000; 2009), Pierre Lévy (1993; 1999), Linton Freeman (1979; 1996; 2002), Stanley Wasserman (1994; 2005), Katherine Faust (1994), John Scott (2005), Peter Carrington (2005), Stephen Borgatti (1999; 2002; 2003), Mark Granovetter (1973; 1983), Bruno Latour (1996; 2005), Fritjof Capra (1996; 2002), Duncan Watts (1998; 1999; 2004), Steven Strogatz (1998), Manuel Castells (1999; 2003, 2010), Chun Wei Choo (2006), Mark Newman (2003; 2006), Rob Cross (2003; 2004; 2005), tem-se assistido, nos últimos anos, ao progressivo crescimento do campo de estudos e aumento de conhecimento sobre redes.

\section{Explorando as definições de rede e rede social}

Para os matemáticos e físicos, uma rede "é um conjunto de itens, que chamamos de vértices (nós), com ligações entre eles, chamados de conexões (arestas)" (CASTRO, 2007, p. 45), no âmbito social, rede é com frequência usada de forma metafórica, significando "sistema de nodos e elos; uma estrutura sem fronteiras; uma comunidade não geográfica, [...] um conjunto de participantes autônomos, unindo ideias e recursos em torno de valores e interesses compartilhados" (MARTELETO, 2001, p. 72).

Tomaél e Marteleto (2006) consideram que uma rede é uma representação formal de atores e suas relações e que uma rede social se refere a um conjunto de pessoas, organizações ou outras entidades sociais "conectadas por relacionamentos sociais, motivados pela amizade e por relações de trabalho ou compartilhamento de informações e, por meio dessas ligações, vão constituindo e reconstruindo a estrutura social" (TOMAÉL; MARTELETO, 2006, p.75).

De forma análoga, Silva e Ferreira (2007) consideram que "rede social é um conjunto de pessoas (ou empresas ou qualquer outra entidade socialmente criada) interligadas por um conjunto de relações sociais tais como amizade, relações de trabalho, trocas comerciais ou de informações".

Como síntese, podemos afirmar que rede social é uma estrutura social composta por indivíduos, organizações, associações, empresas ou outras entidades sociais, designadas por atores, que estão conectadas por um ou vários tipos de relações que podem ser de amizade, familiares, comerciais, sexuais etc. Nessas relações, os atores sociais desencadeiam os movimentos e fluxos sociais, através dos quais partilham crenças, informação, poder, conhecimento, prestígio etc. 
Para efeitos deste trabalho, definimos rede social de informação como uma rede social, ou seja, um conjunto de pessoas, com algum padrão de contatos ou interações, entre as quais se estabelecem diversos tipos de relações e, por meio delas, circulam diversos fluxos de informação.

No entanto, nos primeiros anos deste século, a expressão redes sociais foi associada, quase que exclusivamente, a tecnologias da informação. Por isso, é importante distinguir e não confundir rede social, como definida acima, com os aplicativos de relacionamento (networking social) disponíveis na Internet, tais como Facebook ou MySpace, entre outros. Esses aplicativos digitais podem ser entendidos como manifestações especiais e particulares de algumas redes sociais ou como ferramentas que permitem a explicitação digital de redes tácitas e o estímulo e desenvolvimento de novas redes com características particulares. $\mathrm{Na}$ atualidade, a grande maioria das redes sociais existe independentemente da tecnologia. A tecnologia evidencia e as potencializa, sobretudo nos casos em que o fator espacial impede um contato e uma relação mais próxima.

Entretanto, se pensada do ponto de vista do Ciberespaço e das tecnologias da inteligência de Pierre Lévy (1993), a técnica e a tecnologia é indissociável da realidade social, as tecnologias não são adjetivos sociais, mas sim, parte integrante do coletivo social caracterizando os seus processos sócio-técnicos. Segundo Bell e Gray (1997), nas próximas décadas, assistiremos, por um lado, a um grande desenvolvimento nas tecnologias de interface entre o mundo físico e a rede mundial de computadores e a internet e, por outro, ao aumento da convergência e interoperabilidade de todas as redes.

É possível pensar em um futuro não muito distante, em que grande parte das redes de relações e trocas não materiais seja em ambiente virtual, ao mesmo tempo em que, com o atual nível de desenvolvimento sócio-técnico, não é concebível um mundo sem trocas materiais no mundo físico.

\section{0 método de Análise de Redes Sociais (ARS)}

Análise de Redes Sociais (ARS) é uma ferramenta metodológica de origem multidisciplinar (sociologia, psicologia, antropologia e matemática) e estabelece um novo paradigma na pesquisa, sobre a estrutura social. "A estrutura é apreendida concretamente como uma rede de relações e de limitações que pesa sobre as escolhas, as orientações, os comportamentos, as opiniões dos indivíduos" (MARTELETO, 2001, p. 72).

Se, por um lado, o uso metafórico da ideia de rede social enfatiza que as ligações sociais dos indivíduos, em qualquer grupo social, se enredam por meio desse mesmo grupo, por outro, o uso analítico da ideia de rede social especifica como esse enredamento influencia o 
comportamento das pessoas envolvidas na rede. A abordagem analítica de redes sociais tem os seus próprios postulados teóricos, seus métodos, seus pesquisadores e software de ARS.

A ARS possibilita o delineamento e estudo da estrutura de grupos sociais e das relações e posições dos atores, através de matrizes e/ou de imagens gráficas. Em termos de notação matemática, qualquer rede $\mathrm{R}$ com $\mathrm{N}$ vértices pode ser representada por sua matriz de adjacência $A(R)$, com NxN elementos $A_{i, j}$, em que $A_{i, j}=1$ se os vértices $i$ e $j$ estão conectados e $A_{i, j}=0$, caso contrário. Nos diagramas ou grafos de redes sociais, os atores sociais são representados por pontos e suas relações por linhas. A metodologia enfatiza medidas de posição e poder relativo dos atores, medidas estruturais da rede e medidas de fluxos de recursos trocados entre os atores sociais e é um importante instrumento para estudar relacionamentos que fomentam o compartilhamento da informação e do conhecimento.

A diferença fundamental entre uma explicação de um processo através de rede social e uma explicação desse processo através de outra forma que não rede é a inclusão dos conceitos e informação sobre relacionamentos entre as unidades deste estudo. Em vez de focar nos atributos das unidades individuais, nas associações entre esses atributos ou na utilidade de um ou mais atributos para prever o valor de outro atributo, a perspectiva das redes sociais interpreta as características das unidades sociais como resultado dos processos estruturais ou relacionais, ao mesmo tempo em que valoriza e se focaliza nas propriedades dos sistemas relacionais propriamente ditos (WASSERMAN; FAUST, 1994).

Sintetizando, podemos afirmar que a ARS mapeia e investiga os padrões de relacionamento de atores sociais com base nas suas interações e procura identificar, por meio de indicadores, os efeitos dessas interações nos próprios atores e nas organizações em que se inserem.

\section{Objetivos do estudo de caso}

Este estudo de caso insere-se em um conjunto mais alargado de investigações empíricas desenvolvidas pelo autor, que propõem o estudo concomitante de estruturas organizacionais e fluxos de informação intraorganizacionais.

Todas essas investigações empíricas se caracterizam pelo fato de terem o mesmo assunto (a informação, sua estrutura e seus fluxos); o mesmo lócus (a organização); a mesma metodologia (a ARS); o mesmo problema de pesquisa que se procura recortar, isto é, a forma como os fluxos de informação se relacionam com as topologias e dinâmicas das Redes Sociais Intraorganizacionais pelas quais trafega e é processada essa informação.

Com esse enquadramento, e em linha com objetivos genéricos da ciência da informação, este estudo de caso pretende contribuir para o 
estudo de motivações e necessidades de informação e de como as pessoas procuram, oferecem e utilizam informação no contexto organizacional. Assim, os objetivos gerais do estudo de caso foram:

a) contribuir para o aprofundamento do conhecimento dos ambientes de informação nas organizações, ambientes esses criados pelas estruturas e funções de redes sociais;

b) aplicar a metodologia ARS a redes sociais de informação numa organização;

c) Paralelamente, alguns objetivos práticos e específicos foram também estabelecidos:

d) validar a hipótese de que diferentes atores detêm diferentes níveis de influência, prestígio, independência e capacidade de controle de informação nos processos de procura, oferta e utilização de informação em contexto organizacional;

e) validar a hipótese de que a topologia da rede de fluxos de informação estudada não segue a topologia da estrutura organizacional. A estrutura informal de fluxos de informação é consideravelmente mais complexa do que a estrutura formal; e

f) validar a hipótese de que, em uma mesma organização, diferentes tipos de fluxos de informação têm topologias e dinâmicas também diferentes.

\section{Método do estudo de caso Organ}

Entre fevereiro e março de 2010, foi realizado um projeto de consultoria estratégica em uma organização brasileira de agronegócio que, por motivos de confidencialidade, designaremos por Organ. Esse projeto foi realizado por uma empresa de consultoria de gestão internacional, em um contexto de redesenho organizacional e de processos, para os quais a Organ julgou ser conveniente ter o apoio dessa consultoria estratégica. O autor integrou a equipe de projeto.

Sobre a Organ, esta empresa atua há cerca de 50 anos no mercado, e conta em seu portfólio com mais de 60 produtos para as mais diversas culturas e controle de pragas domésticas; produz fungicidas, herbicidas, inseticidas, nutrientes, produtos especiais, domissanitários e fumigantes. A missão da Organ é contribuir para o progresso e competitividade da agricultura brasileira e a empresa declara que o seu negócio vai além de apenas levar suas soluções ao agricultor, mas passa, também, por oferecer serviços, com o objetivo de auxiliar o produtor rural a obter uma melhor produtividade com a maior qualidade possível e de forma sustentável.

O projeto de consultoria estratégica tinha vários objetivos, para os quais se fez necessária a realização de um diagnóstico de alguns elementos da organização, através de questionários e entrevistas sobre os diversos temas tratados no projeto de consultoria. 
Uma das dimensões do diagnóstico foi a das relações de trabalho que os funcionários chave mantinham, nessa data, na Organ. Em um contexto organizacional, é através das relações de trabalho que as informações fluem ou de outra forma, os funcionários trocam entre si fluxos de informação, através das relações que mantêm, por meio de canais como telefone, email, web, contato direto, etc. Este estudo é resultado da utilização dos dados de questionários e de entrevistas que se referem exclusivamente a essa dimensão do projeto de consultoria, a dimensão das relações de trabalho da Organ.

A seleção dos funcionários entrevistados foi feita pela direção da Organ em conjunto com a equipe de consultoria, predefinindo um grupo de 45 funcionários para responderem ao questionário. Não se utilizaram outras formas de seleção, como poderia ser o snowball sampling, por exemplo, por motivos de custo e tempo do projeto de consultoria. A técnica de snowball foi aventada na fase de desenho do projeto, mas o custo do projeto comprado pela Organ previa um máximo de 60 atores (para mais atores o custo era superior) e um período de recolha de respostas a questionários de, no máximo, duas semanas (para mais tempo o custo era superior). Com essas características do produto de consultoria comprado, a direção da Organ e a equipe de consultoria optaram por predefinir o grupo de 45 funcionários, sobre os quais incidiria a pesquisa, procurando, com os seus conhecimentos da organização, estabelecer um grupo que representasse com acuidade os níveis superiores da estrutura hierárquica e todas as áreas funcionais da Organ.

O questionário foi desenvolvido e disponibilizado em uma plataforma de Internet, e os funcionários escolhidos foram informados do projeto e questionário através de email, enviado pela área de recursos humanos. Esse email apelava à participação, explicando a importância do estudo, informava o período durante o qual as respostas ao questionário deveriam ser dadas (uma semana) e explicava detalhadamente o processo de acesso ao site, entrada e preenchimento do questionário. Dos 45 funcionários selecionados para o questionário, três não responderam. Assim, o total de respostas ao questionário foi de 42 .

No acesso à plataforma do questionário, o objetivo foi reforçado a cada um dos 42 funcionários, isto é, identificar as características da organização através das relações de trabalho que as pessoas chave mantêm entre elas e identificar a organização real, a organização informal. Reforçava-se a importância da veracidade e exatidão das respostas e, por isso, se pedia aos funcionários um esforço neste sentido, no momento em que introduzissem as suas respostas.

Mais especificamente, o trabalho teve como objetivo estudar as redes organizacionais construídas pelas relações e fluxos de trabalho, de inputs críticos e de conselhos na Organ e, para tal, recorreu-se às respostas dadas pelos funcionários a três, das várias perguntas do 
questionário. Essas três questões, que designaremos por Q1, Q2 e Q3, foram:

Q1: "Pense nas pessoas com as que mais se relacionou para realizar seu trabalho nos últimos seis meses. Quais são aqueles com quem tem mais relação? (Máximo sete pessoas)"

Q2: "Algumas pessoas trabalham sozinhas, enquanto que outras dependem de "inputs críticos" para a realização de seu trabalho. Esses inputs podem ser materiais, estudos, informação ou outros. Considere quais "inputs críticos" necessita para a consecução de seu trabalho e quem os fornece. Quais são as pessoas mais críticas no momento de realizar seu trabalho? (Máximo sete pessoas)"

Q3: "Pense nas pessoas a quem recorre para pedir conselho em temas relacionados com seu trabalho ou desenvolvimento profissional (Máximo sete pessoas)"

Para cada relação mencionada, solicitava-se o departamento/área e organização a que pertencia e uma classificação da frequência (5 - diária, 4 - semanal, 3 - mensal, 2 - trimestral e 1 - menos frequente) a e distância (de 4 - próxima a 1 - distante) dessa mesma relação.

Os funcionários que responderam ao questionário foram codificados como $A 1, A 2, \ldots$, até $A 42$, com a distribuição por departamentos e cargos, conforme mostra o quadro1.

Nas suas respostas ao questionário, estes 42 funcionários nomearam 82 outros funcionários da Organ, que codificamos como B1, $B 2, \ldots, B 82$, nomearam Fornecedores codificados como $F$ e Clientes codificados como $C$. Os elementos de $B, C$ e $F$ designaremos por alteres.

Quadro 1 - Caracterização dos atores

\begin{tabular}{lr}
\hline Denartamento & \\
\hline Conselho & 1 \\
\hline Presidência & 1 \\
\hline Alfa & 6 \\
\hline Bravo & 5 \\
\hline Charlie & 3 \\
\hline Delta & 13 \\
\hline Eco & 12 \\
\hline Foxtrot & 1 \\
\hline Total & 42 \\
\hline
\end{tabular}

Fonte: Dados da pesquisa.

\begin{tabular}{lr}
\hline Cargo & \\
\hline Conselheiro & 1 \\
\hline Presidente & 1 \\
\hline Diretor & 3 \\
\hline Subdiretor & 3 \\
\hline Gerente & 19 \\
\hline Vendedor & 8 \\
\hline Analista & 7 \\
\hline & \\
\hline Total & 42 \\
\hline
\end{tabular}

As respostas dos questionários foram armazenadas e organizadas em arquivos Excel. Nesse estágio, procedeu-se à aplicação da metodologia de ARS através da construção das diversas matrizes de adjacência, da construção e cálculo de medidas e indicadores das redes e do desenho dos grafos fazendo uso do Excel, do Ucinet e do NetDraw, sendo as duas últimas ferramentas informáticas, específicas para ARS. 


\section{Abordagem aos papéis e posições dos atores nos fluxos de informação}

Designaremos por rede Organ, a rede constituída por todas as relações que resultaram de Q1, Q2 e Q3. As redes resultantes de cada uma das questões serão designadas por rede de trabalho (Q1), rede de inputs críticos (Q2) e rede de conselhos (Q3). Neste estudo, entende-se que, através da rede de relações de trabalho, podem fluir vários tipos de recursos e insumos para a consecução do trabalho. Informação é certamente um desses recursos, sendo inputs críticos e conselhos considerados dois tipos particulares de informação. Os resultados da ARS da Organ não são, neste trabalho, apresentados de forma exaustiva e, em vez disso, pretendem ser uma ilustração de uma abordagem ao estudo de fluxos de informação, através da aplicação da metodologia de ARS.

A análise e os resultados apresentados neste trabalho referem-se à da rede Organ, isto é, da rede composta pela rede de fluxos de trabalho (informação de relacionamento de trabalho) + rede de fluxos de inputs críticos (informação crítica) + rede de fluxos de conselhos (informação de relações de confiança). Assim, o fluxo de informação que está sendo considerado neste estudo, para a geração de medidas e características de rede, é um fluxo informacional, composto por informação de relacionamento de trabalho, informação crítica e informação de relações de confiança. É de notar-se, ainda, que essa é uma rede de fluxos de informação tácita e explícita, cujas relações ocorrem por contato direto (face a face) e/ou pelo contato indireto, isto é, através mediação como podem ser a Internet, email, telefone, entre outros meios.

Os 42 atores da Organ que responderam ao questionário indicaram um total de 613 relações, das quais 289 foram de trabalho (Q1), 167 de inputs críticos (Q2) e 157 de conselhos (Q3). Cada aresta da rede Organ, no GRAFO 1, indica que existe, pelo menos, um dos três fluxos possíveis entre os atores conectados.

Grafo 1 - Relações totais da rede Organ

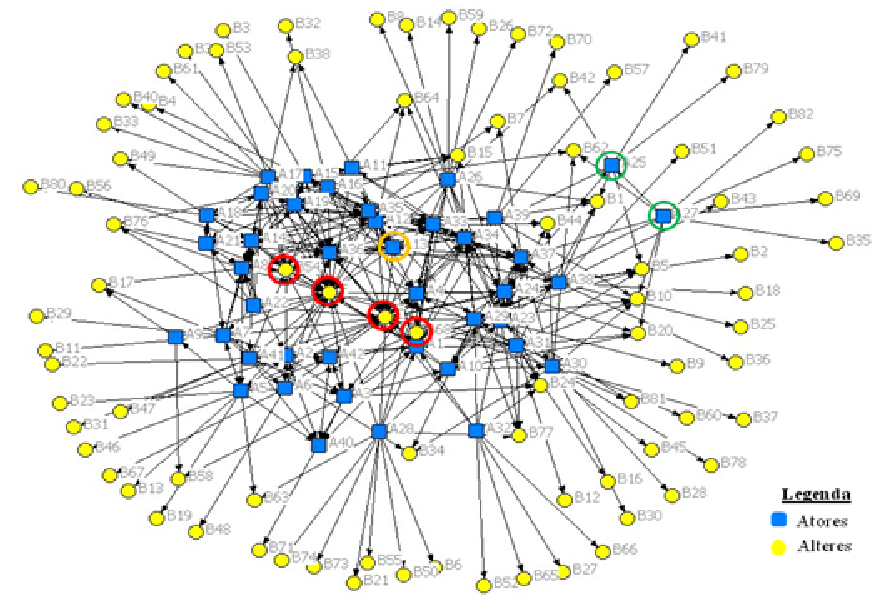

Fonte: Dados da pesquisa. 
Como esperado, os atores concentram-se na região central do grafo, ao passo que os alteres ocupam majoritariamente a periferia. No entanto, há dois atores, A25 e A27 (círculos verdes), que se situam próximo da periferia, porque relataram consideravelmente menos relações com outros atores do que com alteres; 29\% (A25) e 19\% (A27) das relações são com atores, enquanto que um ator mais central, como A13 por exemplo (círculo laranja), tem $79 \%$ das suas relações com outros atores. Por outro lado, há quatro alteres que aparecem bastante centralizados no grafo (círculos vermelhos); $\mathrm{F}$ e $\mathrm{C}$ porque concentram as relações dos atores com Fornecedores e Clientes; B54 que é diretor de área Eco e foi referido como destino de relações de 23 atores; B68, gerente de recursos humanos, tem relações muito estreitas com 7 atores com posições centrais.

Com objetivo de estudar fluxos de informação, importa estudar relações que tenham potencial para serem recíprocas. Esse não é o caso das relações dos nós $B 1, B 2, \ldots, B 82, F$ e $C$, porque só podem ser indicados e não indicar e, por esse motivo, são, neste estudo, designados por alteres e não por atores. Assim, a análise em maior detalhe faz-se por interpretação das redes emergentes das relações de atores com atores, excluindo alteres. Dessa forma, consideramos os atores A1 ... A42 como os nós focais da análise que assim formam a rede completa desta análise.

Analisando com este filtro, verificamos que os 42 atores indicaram um total de 380 relações com os demais atores, das quais 166 foram de trabalho (Q1), 111 de inputs críticos (Q2) e 103 de conselhos (Q3). Também no GRAFO 2, cada aresta indica que existe, pelo menos, um dos três fluxos possíveis entre os atores conectados. Nota-se que as arestas são direcionadas e representam o sentido do fluxo, pelo que uma aresta bidirecional informa-nos que há uma relação recíproca.

Há muitos indicadores para ARS e baseando-nos no trabalho de Robert Hanneman (2001), para o estudo de caso, escolhemos algumas medidas para determinação de atores e relações chave e medidas de poder (prestigio e influência), independência e capacidade de controlar informações por parte dos atores. Como refere Hanneman (2001), da miríade de ferramentas analíticas disponíveis para ARS, não há formas e indicadores certos e/ou errados na abordagem a redes sociais; para cada caso, devemos selecionar um conjunto de ferramentas analíticas, de acordo com os objetivos da análise e características topológicas e de dinâmica da rede que se pretendem enfatizar.

Densidade é a proporção de todas as conexões que poderiam, logicamente, estar presentes. Entre 42 atores é possível serem estabelecidos $\mathrm{Nx}(\mathrm{N}-1)$ relações unidirecionais, isto é, $42 \times 41=1.722$ relações; nesta rede os 42 atores da Organ relataram 236 relações, o que implica uma densidade de relações de 13,7\% - há 13,7\% das relações que poderiam existir. O número total de canais ou relações recíprocas é 861 , 
metade do total de relações unidirecionais. Como as relações se manifestaram através de 181 canais, a densidade de canais desta rede é de $21 \%$. Estes são valores baixos de densidade de rede, mas importa interpretá-los, lembrando que cada ator só podia referir sete relações em cada questão.

Centralidade de Grau (Degree) é o número de ligações que um ator tem com outros atores e representa o poder do ator na rede. OutDegree (OD) é o número de relações ou fluxos saintes e significa a influência do ator e o InDegree (ID) é o número de relações ou fluxos entrantes, significa prestígio. Ambos são normalizáveis pelo número total de relações ou fluxos possíveis, notados por ODN e IDN e quanto mais baixo o valor (entre $0 \%$ e 100\%) mais descentralizada é a rede. Essa medida leva em conta os laços diretos de cada ator.

A rede Organ é bastante descentralizada, sendo particularmente descentralizada na produção dos fluxos trabalho, input crítico e conselhos (OD). Os atores A34, A33 e A13 (assinalados com círculos laranja no GRAFO 2, têm os maiores OD e estão bastante deslocados da média. Esses atores, três gerentes (dois da área Alfa e um da área Eco), são os atores que têm maior capacidade de fazer os outros cientes de seus pontos de vista e, por isso, são os atores de maior influência na rede.

O diretor e um gerente da área Alfa e, ainda, um subdiretor da área Delta (círculos verdes) são os atores com o mais elevado IDN. É com eles que grande parte dos demais atores procuram estabelecer relações, concedendo-Ihes prestígio na rede Organ. Esta medida dá corpo à expressão informação é poder. Entretanto, o prestígio desses atores pode implicar em sobrecarga de informação, redundância ou mesmo incerteza, se pensado à luz da teoria da informação de Shannon e Weaver (CAPURRO; HJORLAND, 2007).

Quadro 2 - Centralidade de grau da rede Organ

\begin{tabular}{|c|c|c|c|c|c|}
\hline OutDegr & OD & ODN & InDegre & ID & IDN \\
\hline Rede & & $15.9 \%$ & Rede & & 25.9 \\
\hline Média & 5.6 & $13.7 \%$ & Média & 5.6 & 13.7 \\
\hline Desv. & 2.5 & $6.2 \%$ & Desv.pad & 4.6 & 11.2 \\
\hline A34 & 12 & $29.3 \%$ & $\mathrm{~A} 1$ & 16 & 39.0 \\
\hline A33 & 11 & $26.8 \%$ & A36 & 16 & 39.0 \\
\hline A13 & 11 & $26.8 \%$ & A4 & 13 & 31.7 \\
\hline
\end{tabular}

Centralidade de proximidade (Closeness) é a distância de um ator em relação a todos os outros na rede, com base na distância geodésica (mais curta). Em grafos direcionados, esta medida subdivide-se em InCloseness, que mede quão próximo o ator está nas relações de entrada (proximidade para ser alcançado), e o OutCloseness, que mede a proximidade para relações de saída (proximidade para alcançar). Quanto mais alta for a medida, mais próximo o ator está dos outros atores e mais central na rede ele estará. Esta medida representa a independência do ator, por significar a possibilidade de comunicação com os demais, com um número mínimo de intermediários, levando em conta, os laços diretos e indiretos de cada ator.

Os atores A1 e A36 (nós vermelhos nos círculos verdes no GRAFO 2) são os que têm maior facilidade de ser alcançados pelos demais atores, sendo, portanto, os que têm maior 
independência para ter prestígio. Os atores A16 e A17 (assinalados com círculo vermelho no grafo 2, são os que, apesar de relativamente periféricos, têm mais facilidade para alcançar os demais, tendo mais independência na possibilidade de serem influentes.

Quadro 3 - Centralidade de proximidade da rede Organ

\begin{tabular}{|c|c|c|c|}
\hline \multicolumn{2}{|c|}{ OutClosene } & \multicolumn{2}{|l|}{ InClosene } \\
\hline Média & 9.86 & Média & 24.76 \\
\hline Desv. pad. & 1.25 & Desv.pad. & 11.41 \\
\hline A16 & 11.17 & A1 & 38.39 \\
\hline A17 & 11.17 & A36 & 37.96 \\
\hline
\end{tabular}

Fonte: Dados da pesquisa.

Centralidade de Intermediação (Betweeness) é a centralidade de um ator que advêm do fato deste se situar nos caminhos geodésicos entre outros atores. Por esse motivo, esta centralidade considera um ator como meio para alcançar outros atores. Esta medida é considerada uma medida de intermediação de informação ou fluxo que corre na rede, caracterizando o poder de controlar as informações e o trajeto que elas percorrem.

O índice de centralização da rede $(7,85 \%)$ é extremamente baixo, indicando uma grande descentralização e, portanto, uma rede onde os nós têm muito pouca capacidade de controlar os fluxos e onde há muitas alternativas aos fluxos de trabalho, inputs críticos e conselhos.

Examinando a centralidade de intermediação normalizada (CIN) de cada ator, verificamos que, apesar do elevado grau de descentralização, os atores A34, A1 e A13 (já mencionados) e A14, A2 e A8 (círculos azuis no grafo 2) denotam uma capacidade diferenciada de controle dos fluxos na rede (QUADRO 4), onde, em média, um ator se situa em 47 caminhos geodésicos e a medida exibe grande variabilidade. Por oposição, os atores A9, A16, A17, A22, A26, A27, A28, A31 e A32 (assinalados com setas no GRAFO 2, não se situam em nenhum caminho geodésico entre outros dois atores, não tendo qualquer poder de controlo de fluxos.

Quadro 4 - Centralidade de intermediação da rede Organ

\begin{tabular}{lcc}
\hline & CIN & \# caminhos \\
\hline Rede & $7.85 \%$ & \\
\hline Média & $2.87 \%$ & 47 \\
\hline Desv. & $3.20 \%$ & 52 \\
\hline A34 & 10.53 & 173 \\
\hline A14 & $9.63 \%$ & 158 \\
\hline A1 & $9.29 \%$ & 152 \\
A2 & $8.43 \%$ & 138 \\
\hline A8 & $7.56 \%$ & 131 \\
\hline A13 & $7.26 \%$ & 119 \\
\hline
\end{tabular}

Fonte: Dados da pesquisa.

Como síntese à abordagem aos papéis e posições dos atores nos fluxos de informação, é possível afirmar que os resultados descritos permitem validar a hipótese de que diferentes atores detêm diferentes níveis de influência, prestígio, independência e capacidade de controle de informação nos processos de procura, oferta e utilização de informação em contexto organizacional. 
Grafo 2 - Relações entre atores na rede Organ Grafo 3 - Cliques na rede Organ
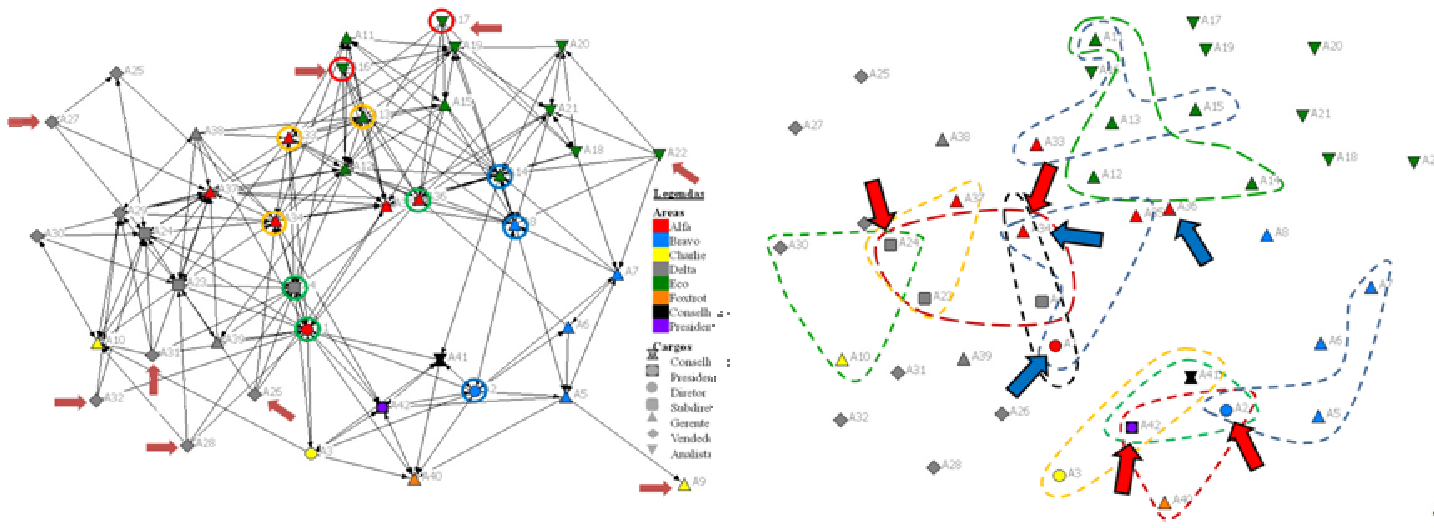

Fonte: Dados da pesquisa.

\section{Abordagem à estrutura da rede}

Clique é um subconjunto de nós de uma rede, no qual os atores estão conectados de forma mais próxima e estreita entre eles do que em relação ao restante da rede. A definição mais forte de clique, que usamos neste trabalho, é um subconjunto da rede em que os seus atores têm entre eles todas as relações possíveis. Os cliques ou pequenos grupos são uma forma tipicamente eficaz de difusão da informação e do conhecimento nas redes. É uma abordagem a atores chave.

Verificamos que na rede Organ, há três cliques com quatro atores e oito cliques com três atores cada (marcados a tracejado no GRAFO 3, onde os atores ocupam as mesmas posições relativas que no GRAFO 2). Quatro atores, A2, A24, A34 e A42 (assinalados com setas vermelhas) destacam-se por pertencerem a três cliques cada um. Também, nesse caso, há uma dispersão do poder de controle de fluxo de informação, na medida em que esses atores são o presidente e representantes de três áreas, Alfa, Bravo e Delta e com três cargos diferentes, diretor, subdiretor e gerente.

Conjunto lambda $(\lambda)$ estabelece o ranking das relações da rede, avaliando quanto dos fluxos entre atores na rede passa por cada uma dessas relações. Com isso, é possível identificar as Pontes, que são as relações que, se retiradas, podem provocar importantes disrupções ou desconexão na rede, originando blocos de atores desconectados entre eles. São canais e relações por onde flui grande parte dos insumos da rede. É uma abordagem a relações chave.

Esta é outra forma de identificar subgrupos coesos e, aplicando essa medida à rede Organ, verificamos que o grupo com o maior valor de lambda é composto por A1, A34 e A36 (quadro 5), assinalados com setas azuis no grafo $3 . \lambda=16$ é o numero mínimo de linhas que têm que ser removidas do grafo, de forma que não seja possível estabelecer nenhuma conexão entre estes três atores (WASSERMAN; FAUST, 1994). Isto quer 
dizer que as relações entre estes atores são as pontes que, se retiradas, causariam maior desconexão na rede. Também, esta medida nos confirma uma rede muito descentralizada porque as relações que se seguem por ordem de valor $\lambda$ são praticamente tão críticas como a primeira. O valor de $\lambda$ decresce lentamente, implicando que, por exemplo, as relações do primeiro grupo com $\mathrm{A} 12(\lambda=15)$ teriam praticamente o mesmo poder de perturbação do fluxo de trabalho, inputs críticos e conselhos desta rede da Organ.

Quadro 5 - Conjuntos lambda e pontes da rede Organ

\begin{tabular}{cl}
\hline$\lambda$ & Coniuntos lambda \\
\hline$\lambda=1$ & $\mathrm{~A} 1+\mathrm{A} 34+\mathrm{A} 36$ \\
\hline$\lambda=1$ & $(\mathrm{~A} 1+\mathrm{A} 34+\mathrm{A} 36)+\mathrm{A} 12$ \\
\hline$\lambda=1$ & $((\mathrm{~A} 1+\mathrm{A} 34+\mathrm{A} 36)+\mathrm{A} 12)+\mathrm{A} 4+\mathrm{A} 14+\mathrm{A} 33+\mathrm{A} 37$ \\
\hline$\lambda=1$ & $((\mathrm{~A} 1+\mathrm{A} 34+\mathrm{A} 36)+\mathrm{A} 12)+\mathrm{A} 4+\mathrm{A} 14+\mathrm{A} 33+\mathrm{A} 37)+\mathrm{A} 8+\mathrm{A} 13+\mathrm{A} 23$ \\
\hline$\lambda=1$ & $(((\mathrm{~A} 1+\mathrm{A} 34+\mathrm{A} 36)+\mathrm{A} 12)+\mathrm{A} 4+\mathrm{A} 14+\mathrm{A} 33+\mathrm{A} 37)+\mathrm{A} 8+\mathrm{A} 13+\mathrm{A} 2$ \\
\hline
\end{tabular}

Fonte: Dados da pesquisa.

A força dos laços fracos de Granovetter diz-nos que aqueles a quem estamos fracamente ligados são mais propensos a mover-se em círculos diferentes dos nossos e, assim, ter acesso à informação diferente daquela que nós temos. Por outro lado, os laços fortes promovem a coesão local na rede. "A força de uma ligação é uma combinação da quantidade de tempo, da intensidade emocional, da intimidade (confidências mútuas), e dos serviços recíprocos que caracterizam o vínculo" (GRANOVETER, 1973, p. 1361). Neste trabalho, apresentamos a determinação dos laços fortes e fracos na rede de trabalho da Organ.

Grafo 4 - Laços fortes e fracos da rede de trabalho da Organ
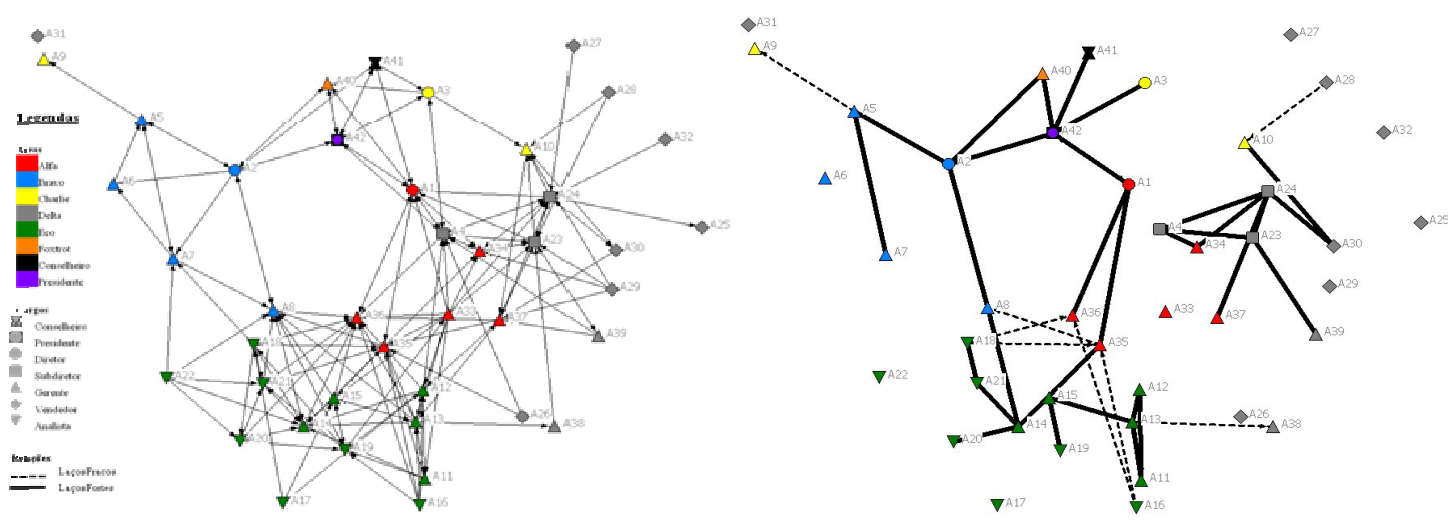

Fonte: Dados da pesquisa.

Tomamos como parâmetros o fato das relações serem bidirecionais ou unidirecionais, a frequência (5 - diária, 4 - semanal, 3 - mensal, 2 trimestral e 1 - menos freqüente) a e proximidade (de 4 - próxima a 1 distante). Definimos laços fortes como os de a maior frequência e proximidade possível, isto é, laços bidirecionais com frequência $(F)=5$ e proximidade $(P)=4$. Definimos laços fracos como os de menor frequência $e$ proximidade possível, isto é, laços unidirecionais com $\mathrm{F}+\mathrm{P}=4$ ou $\mathrm{F}+\mathrm{P}=5$ (GRAFO 4). 
Para Shannon e Weaver a maior liberdade de escolha dos atores está associada a maior sobrecarga de informação, a redundância ou mesmo incerteza. Para Gregory Bateson a informação é uma diferença que faz diferença, como algo que existe independentemente de um observador (CAPURRO; HJORLAND, 2007). Sob esta perspectiva, é possível traçar um paralelo entre estes conceitos de informação e laços fortes e fracos da rede. Os laços fortes tecem uma teia coesa e alimentam os atores por eles conectados com grande quantidade de informação, muitas vezes redundante, podendo levar à incerteza ou dificuldade de decisão, ao passo que os laços fracos possibilitam e trazem o novo, o não esperado, a informação diferente.

Como síntese à abordagem à estrutura da rede, é possível afirmar que os resultados descritos permitem validar a hipótese de que a topologia da rede de fluxos de informação estudada não segue a topologia da estrutura organizacional. A estrutura informal de fluxos de informação é consideravelmente mais complexa do que a estrutura formal.

\section{Comparando redes de trabalho, inputs críticos e conselhos na Organ}

Como vimos no início da análise, a rede Organ pode ser pensada como uma rede de redes, porque é composta por três redes separáveis, a rede de trabalho (Q1) de inputs críticos (Q2) e conselhos (Q3). Toda a análise de papéis e posições dos atores nos fluxos de informação e de estrutura da rede foi igualmente conduzida para cada uma dessas três redes e conclui-se que as quatro redes exibem topologias e dinâmicas diferentes entre si.

Quadro 6 - Centralidades das redes

Network OutDegree

Network InDegree

Network Betweeness

Fonte: Dados da pesquisa.

$\begin{array}{r}\hline \text { Trabal } \\ \hline 17.6 \% \\ \hline 22.6 \% \\ \hline 10.3 \% \\ \hline\end{array}$

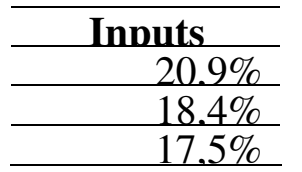

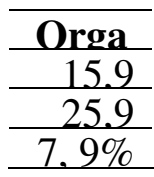

As quatro redes são bastante descentralizadas, merecendo particular ênfase a rede de conselhos com total descentralização no OutDegree, dar conselhos e Betweeness, intermediar conselhos.

Nenhum ator tem elevada influência (OutDegree) nas três redes, em simultâneo. O gerente de Alfa A33, o gerente de Eco A13 e o subdiretor de Delta A24 são ao atores que, por esta ordem, exibem maior influência na rede de trabalho, enquanto que na rede de inputs críticos, só o gerente de Alfa A34 se destaca e, destes quatro, A33, A13 e A34 são os três mais influentes da rede Organ. Entretanto, A8 gerente Bravo, A14 gerente Eco, A38 gerente Delta e A41 o conselheiro, com pouca influência na rede Organ, são os atores com maior influência na rede de Conselhos. 0 gerente de Alfa A36 e o diretor de Alfa A1 são os atores com maior prestígio (InDegree) da rede Organ, porque, A36 é o de maior prestigio nas redes de trabalho e inputs críticos e $A 1$ na rede de conselhos. 
Independência para alcançar (OutCloseness) - O analista de Eco A16, nas redes de trabalho e de conselhos, e os analistas de Eco A18 e A21, na rede de inputs críticos, são os atores que têm maior capacidade para alcançar todos os outros atores. São atores de nível hierárquico inferior, que exibem maior capacidade para chegar até aos demais.

O controle de fluxo (Betweeness) é exercido com maior proeminência por diferentes atores nas diferentes redes: na rede de trabalho é gerente de Bravo A8, na rede de inputs críticos é o gerente de Alfa A34 e na rede de conselhos são o gerente de Eco A14 e o diretor de Alfa $A 1$, que têm maior poder de controlar as informações.

Enquanto a rede Organ tem 11 cliques e os atores $A 2$ diretor de Bravo, A24 subdiretor de Delta, A34 gerente de Alfa e A42 o presidente, pertencem a três cliques cada um, as redes de inputs críticos e de conselhos não têm qualquer grupo de pelo menos três atores com relações recíprocas entre eles (clique). A rede de trabalho tem quatro cliques, nos quais se destaca outro ator, o subdiretor de Delta A4, por pertencer a dois desses cliques.

Alguns atores têm vários papeis de destaque em mais do que uma rede da Organ. São os casos dos atores A1, A14, A34 e A36, o diretor e dois gerentes de Alfa e um gerente de Eco. Entretanto, há vários atores que desempenham papéis centrais em alguma das redes de trabalho, inputs críticos ou conselhos, mas ocupam papéis de menor destaque na rede das redes, a rede Organ: A2, A8, A24 e A35, na rede de trabalho; A18, A21 e A37, na rede de inputs críticos; A8, A14, A38, A40 e A41 na rede de conselhos.

Em todas as redes, o presidente A42 figura em um dos dois quartis mais importantes, mas em nenhuma rede é um dos dois ou três atores com maior prestígio, influência, independência ou controle de fluxo. Estes dados corroboram a ideia de que as redes da Organ têm elevados graus de descentralização.

Como síntese à comparação entre as redes de trabalho, inputs críticos e conselhos na Organ, é possível afirmar que os resultados descritos permitem validar a hipótese de que, em uma mesma organização, diferentes tipos de fluxos de informação têm topologias e dinâmicas também diferentes.

\section{Conclusões}

Como refere Schultz-Jones (2009), as aplicações da teoria e análise de redes sociais têm migrado de uma perspectiva que interpretava as redes apenas como um conjunto estático de objetos (pessoas, grupos, organizações), ligados por uma variedade de relações, para um quadro teórico-analítico de compreensões mais relacionais, contextuais, sistêmicas e dinâmicas. Este trabalho alinha-se com esta última perspectiva e procurou contribuir para 0 aprofundamento do 
conhecimento dos ambientes de informação nas organizações, através da aplicação da metodologia ARS a algumas redes sociais de informação em uma organização.

O estudo de caso possibilitou identificar atores e relações chave nos fluxos de trabalho, inputs críticos e conselhos, ao mesmo tempo em que o desenho dos grafos das redes possibilitou a identificação da organização informal da Organ. Os diferentes poderes estão distribuídos por vários atores, ao mesmo tempo em que os atores de maior prestígio, influência, independência ou controle de fluxo não são os atores de posição hierárquica mais elevada. São normalmente atores de nível intermédio, na estrutura formal da organização, que detêm maior centralidade e poder, sendo que, em alguns casos, há atores de nível hierárquico inferior que desempenham papéis de relevância em alguma das redes. Do ponto de vista de poder individual e capacidade de controle de informação, o estudo mostra que estar localizado em um ponto estratégico da rede é possivelmente mais importante que estar localizado em um determinado nível hierárquico, mesmo que superior.

As redes analisadas são bastante distribuídas e muito coesas, com elevados graus de conectividade. Há semelhanças de estrutura e poder dos atores nas redes de trabalho e inputs críticos, enquanto que a rede de conselhos exibe uma topologia e dinâmica bem diferenciada das anteriores. Entretanto, é importante saber que os resultados dessas ARS não são extrapoláveis a toda a organização, na medida em que representarem as dinâmicas próprias de trânsito de insumos entre estes atores em particular. A articulação entre os conceitos e estruturas de laços fortes e fracos, por um lado, e de conceitos de redundância, ruído, incerteza, sobrecarga de informação e informação nova, não esperada e diferente, por outro, reforça a importância da ARS como ferramenta analítica para o estudo dos fenômenos da informação.

Este estudo de caso forneceu evidências analíticas de que diferentes tipos de recurso em uma organização fluem através de redes diferentes e experimentam topologias e dinâmicas de rede diferentes. Para desenvolvimento de trabalhos futuros de ARS com foco nos fenômenos da informação em organizações, algumas questões de pesquisa podem, desde já, ser levantadas: Como evoluem com o tempo essas topologias e dinâmicas dos diferentes tipos de informação? Há padrões de topologia e dinâmica de rede para os mesmos tipos de informação em organizações diferentes? Em uma perspectiva de gestão de redes sociais de informação, que ações podemos tomar, de forma a aumentar a capacidade de procurar, oferecer, encontrar e usar informação no contexto organizacional?

Reconhecer a complexidade do comportamento humano na procura, oferta, troca e uso de informação sugere a utilização de caminhos teórico- 
analíticos, que possam capturar essa complexidade. A ARS parece ser um desses promissores caminhos.

\section{Referências}

BARABÁSI, A.-L.; ALBERT, R. Emergence of scaling in random networks. Science, v. 286, p. 509-512, 1999.

BARABÁSI, A.-L.; ALBERT, R.; JEONG, H. Scale-free characteristics of random networks: the topology of the World Wide Web. Physica $A$, v. 281, p. 69-77, 2000.

BARABÁSI, A-L. Linked: a nova ciência dos networks. São Paulo: Leopardo, 2009.

BARAN, P. Rand Memoranda on Distributed Communication. Disponível em:

< http://www.rand.org/pubs/research_memoranda/2006/RM3420.pdf>. Acesso em: 15 abr 2010.

BELL, G.; GRAY, J. The revolution yet to happen. In: DENNING, P. J.; METCALFE, R. M. (Orgs.). Beyond calculation: the next fifty years of computing. New York: Copernicus, 1997. p. 2-23.

BOTT, H. Observation of play activities in a nursery school. Genetic Psychology Monographs, n. 4, p. 44-88, 1928.

BORGATTI, S.; EVERETT, M. G. Models of core/periphery structures. Social Networks, v. 21, p. 375-395, 1999.

BORGATTI, S. P.; EVERETT, M. G; FREEMAN, L. C. UCINet 6: v. 6.278 for Windows: software for social network analysis. Harvard, MA: Analytic Technologies, 2002.

BORGATTI, S. NetDraw: graphic visualization software. Harvard: Analytic Technologies, 2002.

BORGATTI, St.; CROSS, R. A relational view of information seeking and learning in social networks. Management Science, v. 49, n. 4, p. 432-445, 2003.

BORGATTI, S.; FOSTER, P. C. The network paradigm in organizational research: a review and typology. Journal of Management, Miami, v.29, n.6, p. 991-1013, 2003.

BURT, R. S. Structural holes: the social structure of competition. Cambridge; Massachussets; London: Harvard University Press, 1995.

CAPRA, F. A teia da vida: uma nova compreensão cientifica dos sistemas vivos. São Paulo: Cultrix, 1996.

CAPRA, F. As conexões ocultas: ciência para uma vida sustentável. São Paulo: Cultrix, 2002.

CAPURRO, R.; HJORLAND, B. O conceito de informação. Perspectivas em ciência da informação, Belo Horizonte, v. 12, n. 1, p. 148-207, 2007. 
CARRINGTON, P. J.; SCOTT, J.; WASSERMAN, S. Models and methods in social network analysis. Cambridge: Cambridge University Press, 2005.

CASTELLS, M. A sociedade em rede. 11 ed. São Paulo: Paz e Terra, 1999.

CASTELLS, M. Internet e sociedade em rede. In: MORAES, D. (Org.). Por uma outra comunicação: mídia, mundialização cultural e poder. Rio de Janeiro; São Paulo: Record, 2003.

CASTELLS, M. Redes sociais e transformação da sociedade. In: CADERNOS RUTH CARDOSO. Centro Ruth Cardoso. [s.l.: s.l.], 2010. p. 89-96.

CASTRO, P. A. Rede complexa e criticalidade auto-organizada: modelos e aplicações. 2007. Tese (Doutorado em Física) - Instituto de Física de São Carlos, Universidade de São Paulo, 2007.

CHEVALEVA-JANOVSKAJA, E. Groupements spontanés d'enfants à l'age préscolaire. Archives de Psychologie, v. 20, p. 219-223, 1927.

CHOO, C. W. A organização do conhecimento. 2. ed. São Paulo: Senac, 2006.

CROSS, R. L.; PARKER, A. The hidden power of social networks: understanding how work really gets done in organizations. Boston: Harvard Business School Publishing, 2004.

CROSS, R. L.; LIEDTKA, J.; WEISS, L. A practical guide to social networks. Harvard Business Review, v. 83, n. 3, p. 124-132, Mar. 2005.

ERDÖS, P.; RÉNYI, A. On random graphs. Publicationes Mathematicae, v. 6, p. 290-297, 1959.

ERDÖS, P.; RÉNYI, A. On the evolution of random graphs. Publications of the Mathematical Institute of the Hungarian Academy of Sciences, v. 5, p. 17-61, 1960.

ERDÖS, P.; RÉNYI, A. On the strength of connectedness of a random graph. Acta Mathematica Scientia Hungary, v. 12, p. 261-267, 1961.

ERDÖS, P.; TURAN, P. On some problems of a statistical group theory III. Acta Math. Acad. Sci. Hungar, v. 18, p. 309-320, 1967.

ERDÖS, P.; TURAN, P. On some problems of a statistical group theory IV. Ada Math. Acad. Sci. Hungar, v. 19, p. 413-435, 1968.

FREEMAN, L. C. Centrality in social networks: conceptual clarification. Social Networks, v. 1, n. 1, p. 215-239, 1979.

FREEMAN, L. C. Some antecedents of social network analysis. Connections, v. 19, n. 1, p. 39-42, 1996.

GRANOVETTER, M. The stength of weak ties. The American Journal of Sociology, v. 78, n. 6, p. 1360-1380, maio 1973.

The stength of weak ties: a network theory revisited. Sociological Theory, v. 1, p. 203-233, 1983. 
HAGMAN, E. P. The companionships of preschool children. University of Iowa Studies in Child Welfare, v. 7, p. 10-69, 1933.

HANNEMAN, R. A. Introduction to social network methods. 2001. Disponível em: <http://faculty.ucr.edu/ hanneman/networks/nettext.pdf>. Acesso em: 11 fev. 2010.

HUBBARD, R. M. A method of studying spontaneous group formation. In: SWAINE, D. (Ed.). Some new techniques for studying social behavior. New York: Teachers College, Columbia University, Child Development Monographs, 1929. p. 76-85.

LATOUR, B. On actor-network theory: A few clarifications plus more then a few complications. 1996. Disponível em: <http://www.cours.fse.ulaval.ca/edc-65804/latour-clarifications.pdf>.

Acesso em: 11 fev. 2010.

LATOUR, Bruno. Reassembling the Social: An Introduction to ActorNetwork-Theory. New York, Oxford University Press Inc., 2005.

LÉVY, P. As tecnologias da inteligência. São Paulo: Editora 34, 1993.

LÉVY, P. Cibercultura. São Paulo:Editora 34, 1999.

MARTELETO, R. M. Análise de redes sociais: aplicação nos estudos de transferência de informação. Ciência da Informação, Brasília, v. 30, n. 1, p. 71-81, 2001.

MARTELETO, R. M. Informação, redes e redes sociais: fundamentos e transversalidade. Informação \& Informação, Londrina, v.12, n. esp., 2007.

MILGRAM, S. The small world problem. Psychology Today, v. 1, n. 1, p.6167, May 1967.

MORENO, J. L. Who shall survive? Washington, DC: Nervous and Mental Disease Publishing Company, 1934.

NEWMAN, M. E. J. The structure and function of complex networks. SIAM Review, v. 45, n. 2, p. 167-256, 2003.

NEWMAN, M. E. J. Modularity and community structure in networks. Proceedings of the National Academy of Sciences, v. 103, n. 23, p. 85778582, 2006.

SCHULTZ-JONES, B. Examining information behavior through social networks. Journal of Documentation, v. 65, n. 4, p. 592-631, 2009.

SILVA, A.; FERREIRA, M. Gestão do conhecimento e capital social: as redes e sua importância para as empresas. Informação \& Informação, Londrina, v. 12, n. esp., 2007.

TOMAÉL, M. I.; MARTELETO, R. M. Redes sociais: posição dos atores no fluxo da informação. Encontros Bibli: Revista Eletrônica de Biblioteconomia e Ciência da Informação, n. esp, p. 75-91, 2006. Disponível em: 
<http://www.periodicos.ufsc.br/index.php/eb/article/viewFile/342/387>. Acesso em: 15 abr 2010.

WASSERMAN, S.; FAUST, K. Social network analysis: methods and applications. Cambridge: Cambridge University Press, 1994.

WELLMAN, B. The school child's choice of companions. Journal of Educational Research, v.14, p. 126-132, 1926.

WATTS, D. J.; STROGATZ, S. H. Collective dynamics of 'small-world' networks. Nature, n. 393, p. 440-442, 1998.

WATTS, D. J. Small worlds: the dynamics of networks between order and randomness. Princeton, NJ: Princeton University Press, 1999.

WATTS, D. J. The "new" science of networks. Annual Review of Sociology, v.30, p. 243-270, 2004. 